\title{
The Impact of Knowledge Documentation Process as an Intermediary Variable among Knowledge Acquisition Process, Organizational Culture and Human Capital
}

\author{
Farah Hanna Saleem Zawaideh ${ }^{1}$, Mohammad Issa Al-Zoubi ${ }^{1}$, Shadi Habis Abualoush ${ }^{1}$, Raed Kareem Kanaan ${ }^{2} \&$ \\ Ra'ed Masa'deh ${ }^{3}$ \\ ${ }^{1}$ Department of Management Information Systems, Faculty of Administrative Science and Finance, Irbid \\ National University, Jordan \\ ${ }^{2}$ Amman Arab University, Amman, Jordan \\ ${ }^{3}$ Department of Management Information Systems, School of Business, The University of Jordan, Amman, \\ Jordan \\ Correspondence: Farah Hanna Saleem Zawaideh, Department of Management Information Systems, Faculty of \\ Administrative Science and Finance, Irbid National University, Jordan. E-mail: Dr.farahzawaideh@inu.edu.jo
}

Received: February 27, 2018 Accepted: September 20, 2018 Online Published: October 25, 2018

doi:10.5539/mas.v12n11p151 URL: https://doi.org/10.5539/mas.v12n11p151

\begin{abstract}
The aim of this paper is to investigate the impact knowledge acquisition process, knowledge documentation process, on human capital, and impact organizational culture on documentation process, Accordingly, a questionnaire-based survey was designed to test the aforementioned model based on dataset of 302 employees' from the National Agriculture Research Center (NARC) in Jordan, questionnaires which include 29 items were used to gather information from the respondents. Multiple regression and simple regression analyses were conducted to test the research hypotheses. This study identified knowledge acquisition and knowledge documentation are the most important factors affecting the accumulation of human capital. The results indicated that knowledge acquisition process and knowledge documentation process positively and significantly affect human capital. However, organizational culture did not prove to be positively related to knowledge documentation process. Moreover, knowledge documentation process positively and significantly mediated the relationship between knowledge acquisition process and human capital. The results have enormous implication for the government sector in Jordan.
\end{abstract}

Keywords: knowledge management, knowledge acquisition process, knowledge documentation process, human capital, organizational culture, Jordan

\section{Introduction}

Knowledge-based economy is a new type of economy today which employs organizational knowledge and Intellectual Capital (IC) as primary means for attaining competitive advantage (Alavi and Leidner, 2001; Masa'deh et al., 2008; Huang and Wu, 2010; Adewale and Anthonia, 2013; Ho et al., 2014; Al Saifi, 2015; Tarhini et al., 2015; Alkandari et al., 2017), particularly in the context of organization. The market today is greatly multifaceted owing to diminishing barriers to market entry, growing competition, briefer life cycles of product, and growing risk. Hence, the elements contributing to corporate competitiveness and success are no longer the same as before. In the past two decades Academicians and management leaders have explored the importance of Knowledge Management (KM) as an instrument for attaining innovation and competitiveness (Akbari and Ghaffari, 2017). Furthermore, KM has become critically important whereby it has attracted interest among people and has become an important topic in discourses (Akhavan et al., 2014a) for both public and private sector.

Knowledge considered being a key resource in the context of government services. Effective acquisition and documentation of knowledge has become a considerable challenge to government organizations in their attempt to achieve better accountability as well as achieving excellence in public services (Analoui et al., 2012). In addition, the acquisition of knowledge from outside sources has been found to be among the essential methods for the reconstruction of knowledge and capacity. As a result, for a firm, in attaining its strategic rejuvenation, 
learning from outside sources will enable it to extend its base of knowledge, improve opportunities and threats identification, while permitting entry to new market (Al-dujaili et al., 2012; Masa'deh, 2016). In this regard, knowledge documentation, which formalizes and codifies knowledge, becomes a vital process associated with knowledge. Knowledge documentation has gained substantial amount of attention as it plays a crucial role in the institutionalization of knowledge. The documentation of knowledge enables knowledge to be kept within the organization in many forms such as manuals, reports, databases, and work procedures as well (Alavi and Leidner, 2001).

The competency of a firm in its management of IC assets is always associated with its capacity in KM. Indeed, $\mathrm{KM}$ and IC are interrelated to each other as both embraces each aspect of intellectual activities in an organization from the generation of knowledge for the purpose of leveraging knowledge. KM comprises a process to optimize the effective use of intellectual capital for the attainment of organizational objectives (Al-dujaili, 2012; Mikkawi and Al-Lozi, 2017). The knowledge-based viewpoint, which is tactical and operational in its nature, posits that the most essential production means are intangible. KM appears to be more in depth and revolves around the facilitation and management of activities associated with knowledge (i.e., the activities of creation, capture, change and utilization). In other words, KM involves planning, implementing, operating as well as monitoring all programs and activities associated with knowledge which are necessary for effective management of IC. With $\mathrm{KM}$, right kind of knowledge can be timely accessed by the right people, in dealing with the environments of the organization that are multifaceted and turbulent in its nature (Felício et al., 2014).

IC if effectively applied will lead to the achievement of objectives set by the organization. Furthermore, the expansion of knowledge economy and knowledge society worldwide has generated awareness amongst organizational leaders on how important are human capitals to their organizations (Filius et al., 2000; Kateb, 2015); the primary emphasis of knowledge-based view is human capital. Human capital comprises employees' knowledge, competences, skills; experience, attitude, and motivation, in addition to how these skills are applied to bring benefit to the organization (Chang and Lin, 2015; Bavik, 2016). Human capital possessed by organization can be considered to be a valuable resource and plays a significant role in the organization's attainment of sustainable competitive advantages (Azmawani et al., 2013); however investment in human capital and information technology may lead to the success of an organization. In the context of IC, human capital is its core element (Azmawani et al., 2013).

A gap that explores the linkage between Knowledge Acquisition Process (KAP) and Human Capital (HC) seems to be existing in the literature. Further, studies that investigated the impact of knowledge acquisition regarding human capital in Jordan's government sector, particularly with knowledge documentation as intermediate variable, are yet to be conducted. As well as organizational culture as an influential factor in the knowledge documentation, As such, public sector organizations should have the awareness of the linkage between KAP, Knowledge Documentation Process (KDP) and HC, taking into consideration that the majority of them have higher likelihood to lose their human capital to the shortcoming associated with incentives, as well as to the easiness of securing leave of long-term.

This study primarily aims to explore the role of knowledge documentation intermediary variables and the relationship between knowledge acquisition and human capital. To achieve this aim, a dataset collected from government organization called NCRA will be employing.

\section{Research Background}

\subsection{Knowledge Management}

$\mathrm{KM}$ has been a topic of interest among many researchers due to its potential contribution to organizational success. In essence, knowledge comprises a fluid combination of enclosed experience, values, circumstantial information, and expert acumen which presents a framework for the assessment and incorporation of novel information and experience (Nonaka and Takeuchi, 1995; Subramaniam and Youndt, 2005). Knowledge comes from and is implemented in the knower's mind (Dahiyat and Al-Zu'bi, 2012; Edvardsson, 2008). Obviously, KM relates to the development, sharing and application of knowledge inside an organization for the purpose of obtaining and sustaining a competitive advantage, due to the fact that it supports more effective knowledge acquisition, documentation, and transfer (Edvardsson, 2006; Gold et al., 2001). Currently, the application of KM are common among firms and organizations, as it enhances product innovation, decision making, profits, and productivity as well (Gamerschlag, 2013). Organizations can apply the process of KM to discover, choose, organize, distribute, and transfer considerable amount of information and expertise required to solve problem, while making possible the dynamic learning, decision making and strategic planning (Ha et al., 2015, Abualoush et al.,2018). KM also represents the capacity of an organization which enables the integration of people, 
technologies, processes and strategy inside the organization itself, for the purpose of generating, acquiring, applying, documenting and sharing of knowledge (Edvardsson, 2006).

In addition to creating, acquiring, documenting knowledge, KM is also associated with retrieving, using, and reviewing of organization's knowledge assets in a manner that is controlled (Birasnav and Rangnekar, 2010). Further, KM helps organization in the organizing, planning, motivating and governing people, processes and systems; in order that organization can assure that its knowledge-related assets are always improved and utilized in an effective manner (Ha et al., 2015). KM systematically and coherently coordinates the general organizational activities. These may include the attainment, generation, storage, documentation, sharing and usage of knowledge by groups and individuals for the accomplishment of the objectives set by the organization (Kamaruzzaman et al., 2016). According to Marr et al. (2004), KM is viewed as a process and activities associated with management practiced by organization to achieve improved effectiveness in the production as well as maintenance of intellectual assets of organization.

Honarpour et al. (2012) pointed out to the exploitation of the already available knowledge, the satisfaction of the present needs, and the establishment of fresh opportunities. Similarly, it is associated with the identification and leverage of knowledge shared within organizations assistance to the organization in competing in the market (Chang and Lin, 2015). In addition to the processes of knowledge (e.g., creation, sharing, acquisition, transfer and application of knowledge), $\mathrm{KM}$ is also equipped with infrastructures, competences and activities of management that support and improve the processes of knowledge (Chang and Lin, 2015). As implied in the literature knowledge management is measurable using countless various processes. For instance, five processes of KM have been highlighted (Ramadan et al., 2017, Abualoush et al., 2018) namely: knowledge acquisition, knowledge creation, knowledge documentation, knowledge transfer, and knowledge application. On the other hand, Obeidat et al. (2017) were suggested three other processes of KM namely: knowledge acquisition, knowledge conversion and knowledge application.

Apparently, there are several processes of KM that have been proposed by different scholars. According to Lin (2014) when these processes integrated into the processes of work, this could remedy dysfunctional organizational behavior. To conclude, $\mathrm{KM}$ is a process that involves many different activities. Alavi and Leidner (2001) claiming that four general processes should be considered, these are as follows: creating, storing/retrieving, transferring, and applying, of knowledge. Such processes are breakable into the generation of internal knowledge, acquisition of external knowledge, and storage of knowledge in documents as opposed to storage of knowledge in routines (Analoui et al., 2012). Accordingly, in line with the current study's objectives, the focal point of this paper is on the KM processes of knowledge acquisition, and knowledge documentation, as the KM measures grounded on the previous works. Each process is highlighted the next paragraphs.

\subsection{Knowledge Acquisition Process}

The success of any organizations mainly driven by knowledge. Moreover, approximately $90 \%$ of organizational knowledge is located in the minds of its employees, thus knowledge acquisition is a crucial KM process in organizations because it enables organizations to increase their performance and effectiveness via the improvement of the breadth and depth of the knowledge that is accessible to them (Khan et al., 2012; Kushwaha and Rao, 2015). The success of individuals in being competitive in the job market is greatly factored by KAP and learning (Lavie, 2006). The acquisition of knowledge from outside sources is crucial for the reconfiguration of knowledge and capacity (Liao et al., 2009). Meanwhile, both inside and outside sources would be referred by employees who lack knowledge. Employees would also employ both sources in upgrading their skills. Universities and professional training institutions are among the sources of knowledge. Furthermore, it is possible to acquire tacit knowledge and explicit knowledge, and both may lead to the generation of a competitive advantage for both learners and their corresponding organization (Lavie, 2006).

In establishing and improving fresh skills in the context of work, acquisition of new knowledge appears to be indispensable. This is factored by the fact that the employees' comprehension and the effectiveness in learning are considerably taken into account by organization in their acquisition of corporate knowledge (Dahiyat and Al-Zu'bi, 2012). Organizations can improve their knowledge assets by obtaining knowledge from both inside and outside, and this consequently contributes to the modification of knowledge (Durst and Edvardsson, 2012), and knowledge acquisition is in fact a pre-requisite for new competences of organization. As asserted by Petruzzelli et al. (2009), the efficiency of external acquisition processes appears to have positive correlation with cognitive proximity, whereas the capacity in acquiring new knowledge from an outside source appears to be a form of integrative competence. Acquisition of knowledge relates to the practices of organization in gathering information from external sources (Chang and Lin, 2015), and also a process of gathering information 
gainedfrom diverse outside sources and having it embedded inside the already available knowledge of individual (Mehralian et al., 2014).

For any organization, external networks and collaborative arrangements are crucial knowledge sources, which customers in turn make up a particularly crucial group that provides knowledge to further assists in the success of organization. For instance, collaboration with partners and research institutions is among the practices that lead to high level of knowledge acquisition (Chang and Lin, 2015). Knowledge acquisition relates to knowledge/information search, identification, selection, collection, organization, and mapping as well (Liao et al., 2009), however the definition of knowledge acquisition may differ at different levels. In particular, at individual level, knowledge acquisition involves change that occurs within the mental model or cognitive structure and the intent to utilize knowledge (Birasnav et al., 2011). Similarly, knowledge acquisition is about gaining knowledge from the outside environment and having it transformed in order that the organization can apply it (Khan et al., 2012; Masa'deh et al., 2017). Likewise, it comprises a mechanism which allows a firm to deliberately incorporate new technologies, ideas and savoir-faire to its already available knowledge foundation from the outside environment. Within the dynamic and innovative environments, this acquisition is of important for organizations to constantly use a vast range of greatly specialized expertise, technologies, and competences which cannot be easily established by a single firm internally (McCann and Buckner, 2004).

According to Nonaka and Takeuchi (1995), it is obvious that knowledge management inside the organization is part of the developing processes which necessitates knowledge. Accordingly, two major means for knowledge gathering have been identified by (Analoui et al., 2012) these are: to seek and attain completely new knowledge, and generate novel knowledge from the already available knowledge by way of collaboration between people and between partners of business. Collaboration with other organizations is crucial to knowledge acquisition (Analoui et al., 2012).

\subsection{Knowledge Documentation Process}

Knowledge documentation formalizes and codifies knowledge, and it is crucial in the institutionalization of knowledge. Documentation in itself is the instruments for knowledge elicitation for the purpose of transforming tacit knowledge into explicit knowledge (Alavi and Leidner, 2001). Within the lifecycle of a project, all project members document their activities during the project scale so that project knowledge can be preserved. Hence, experience documentation can become a tool that allows organizations, particularly those that are project-based, to improve the actions and policies required when dealing with the exact issues and challenges, while also assisting organization in avoiding the same mistakes and in achieving the goals set quicker. With knowledge documentation, knowledge can be placed within the organization in different forms such as reports, work procedures, manuals, and databases (Alavi and Leidner, 2001; Akhavan et al., 2014a).

Meanwhile, organizational memory is established via experience documentation, and it refers to the capacity of organization in implementing the knowledge previously acquired. It is also linked to knowledge and feedback of experience (Ranjbarfard et al., 2014). Organizational memory comprises knowledge documentation in the cognizance perception of organizational partakers. This documentation is kept within electronic repositories attained and maintained by groups or teams entrenched within the processes, products or services of businesses. The relationship that is present between knowledge documentation and customers, partners and suppliers, has placed information as the organization's memory kept in numerous forms (e.g., written documents, electronic databases, processes and procedures of organization, codified knowledge in expert systems, and tacit knowledge that individuals possess) (Navidi et al., 2017).

Knowledge documentation comprises the processes that enable the maintenance, organization, facilitation, accessibility and easy access of knowledge. Information technologies are heavily employed during the process (Sangari et al., 2015). The codified knowledge is kept in electronic databases, whereas human knowledge is placed within expert systems. Meanwhile, tacit knowledge is obtained from individuals, and documenting tacit and implicit knowledge is a crucial process for organizations with high rates of turnover (Mian et al., 2009). This type of organization has unstable staffs because of its temporary employment formulas over short-term contracts, as these staffs may not remain in the organization for long. Hence, implicit knowledge which is possessed by these staffs can be lost when not documented. It also comprises the process of selective preservation of information, documents and experience that management needs. Accordingly, knowledge stocking has been viewed as the firm's knowledge repository, resulting from the buildup of knowledge assets over time (Mian et al 2009).

\subsection{Organizational Culture}

Knowledge management is a major component in the competency of organization in achieving the full prospect 
of its intellectual assets in the generation of a competitive advantage as well as in its strategic and tactical decision making (Hsieh et al., 2002; Bose, 2004; Rowley, 2004). KM also has high impact on business management's success or failure. As assurance that KM is successfully implemented, the key enablers must be attained as assurance that the restricted resources of the organization are effectively used, while decreasing manpower, material, and time utilization with the predicted results still achieved (Meng et al., 2016). The enablers of KM comprise the mechanism utilized by the organization in the development of its knowledge and also in stimulating the fabrication and acquisition of knowledge inside the organization, together with its sharing, documentation or storing. These enablers also make up the core foundation in improving the effectiveness KM related activities. Among the KM enablers are: people, KM methods, information technology, organizational structure, and strategies (Akhavan et al., 2014a).

Organizational culture (OC) does exist in almost all organizations including enterprises, government divisions, non-profit groups, as well as public institutions. This concept is frequently too striking and debatable (Ortiz et al., 2017), but it assists people in understanding the ostensible differences in approaching business among managers coming from different environment of culture. Also, a match between cultural characteristics and management practices has been frequently viewed to be a crucial factor in the fruitful management practices implementation (Nonaka and Takeuchi, 1995). Awareness of organizational culture greatly assists in the formation of employee behavior and it also desirably contributes to the delivery of organizational effectiveness (Shannak and Obeidat, 2012; Obeidat et al., 2017).

Hence, the establishment of solid comprehension towards organizational culture in addition to the manner in which it might optimally be measured is of important for the management of organizations. This understanding would enable the accurate alignment of the goals of the employees with those that the organization had set (Obeidat et al., 2017). There are four aspects to organizational culture as follows: collective behavioral rules, norms and rituals for internal and external organization (Ortiz et al., 2017), patterns of interaction of staffs and groups with one another, clients and stakeholders. Organizational culture can be viewed as the understanding shared by the employees of the organization, particularly in terms of how things are done within the organization. Such concept is also dubbed organizational culture. These concerns focus mainly on beliefs, values, and ethical behaviors, whereby culture is broken down into bureaucratic form, innovative form, and supportive form (Obeidat et al., 2017).

The notion of $\mathrm{OC}$ is described as beliefs and values shared inside the organization, which assist in forming the patterns of behavior of employees (Claver-Corté et al., 2015). On the other hand, in delineating the notion of OC, Khan et al. (2012) focused on work practices rather than values. Accordingly, the authors view OC as the group of certain functions of organization executed by the members in specified manner, making it distinct from other organizations or from other divisions inside the same organization. In the context of this study, OC comprises an exclusive set of the utmost standard of value, core beliefs, as well as norms of behavior that are adhered by nearly all members of the organization members, which is grounded upon the strategy of business established by the organization in long-term development and survival. OC is an implicit be exemplified in the awareness of group such as values, rules of conduct, style of working, sense of belonging, team awareness and so forth, in addition to the behavioral expression of individual and his or her thinking mode.

\subsection{Human Capital}

The success of an organization is associated with the flow of investment in information technology and human capital. Human capital has gained considerable amount of interest in the domain of knowledge economy. This is because this type of economy regards knowledge to be the key factor of development, whereby qualified and educated people become this economy's leading force (Birasnav and Rangnekar, 2010). Entrepreneurs in possession of greater amount of human capital have more likelihood to come across opportunities and elicit initiatives for the generation of their own businesses as these entrepreneurs have higher level of self-confidence and lower level of vulnerability in risk taking (Bastos, 2017).

Human capital depicts the core element of intellectual capital. For organizations, the establishment of human capital requires competence that includes experience, skills, knowledge, experience, expertise, and capacities as well (Boateng et al., 2014). Human capital not only includes elements such as knowledge, skills and capabilities possessed by individuals, but also the ability to produce all the aforementioned resources. Human capital comprises all knowledge that is acquired by people and groups and it is completed by these people or group's competences in learning and sharing this knowledge with others to generate benefit to the organization (King, 2009).

Human capital comprises a set of knowledge, skills, and capabilities that an individual has acquired and uses 
(Boateng et al., 2014). Yusoff et al. (2004) affirmed that human capital entails a type of intellectual capital which is a resultant of the mixture of attributes including skills, knowledge, attitudes, and relationships established in the person's mind, body, and acts. In the context of organization, human capital has also linkage to knowledge, skills, expertise, capabilities, commitment, health, and ideas that the employee possesses (Ramadan et al., 2017). Organizations are thus obliged to invest their resources in order to assure that the employees are equipped with the information, skills, and capacities needed in order that they could effectively perform their tasks in the complex and turbulent environment. In this regard, investments in the development of human capital should be ventured by the organization, this investment part of an overall endeavor for the achievement of outcomes that are timely and also cost-effective (Birasnav and Rangnekar, 2010).

\section{Theoretical Framework and Hypotheses Development}

The review of literature has led to the construction of the theoretical model (Figure 1). This model addresses the interrelationships that exist among knowledge acquisition process (KAP), knowledge documentation process (KDP), and Human Capital (HC). This model is referred in the research hypotheses construction which is highlighted the ensuing subsections.

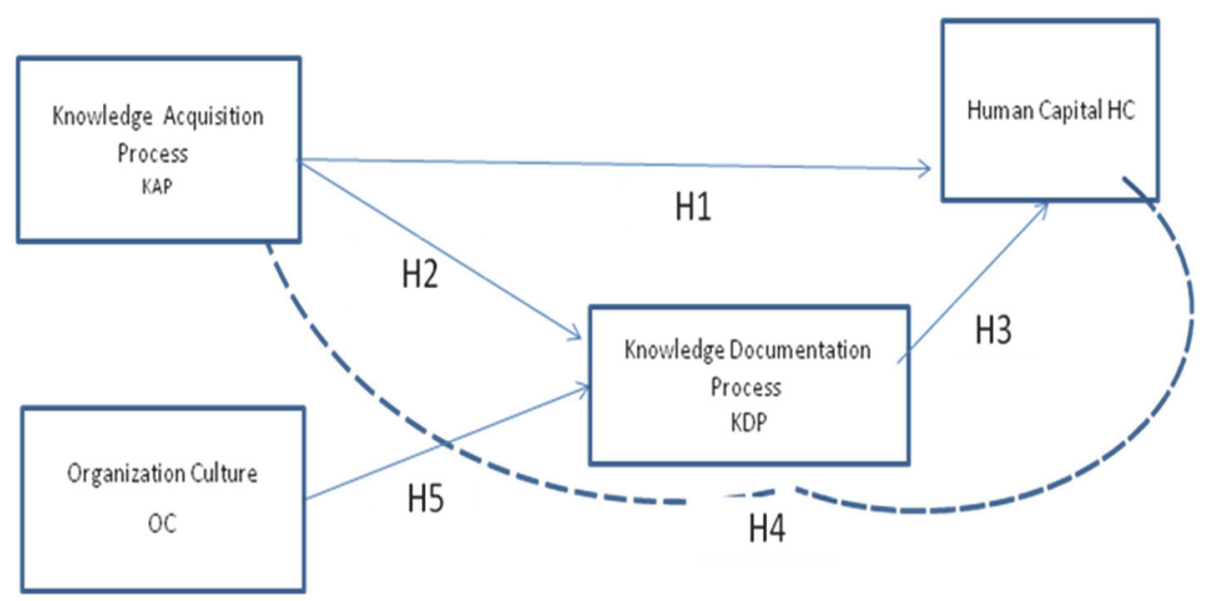

Figure 1. Research model

\subsection{The KAP-KDP-HC Relationship}

In knowledge-based economy, knowledge and intellectual capital (IC) are considered to be the most important resources for organizations to achieve the competitive advantage. Intellectual capital management dictates the success of organizations (Dehghani and Akhavan, 2017). For companies that are knowledge-based, knowledge generation, sharing, documentation, and integration drive the value of organization and its sustainable operations (Azmawani et al., 2013). KM process and practices are applied by organization in order to increase the effectiveness of their IC creation and use. Hence, it is possible that KM play a role in the generation and growth of IC.KMP catalyzes the capture, generation, sharing, use, as well as documentation of knowledge; the ultimate goal is to generate and maximize IC (Azmawani et al., 2013). Within the context of KM, prioritizing the organizational employees will make the achievement of organizational performance faster. Accordingly, organizations would initiate the generation of awareness among their employees pertaining to the advantages of KM programs on the employees and on the performance of the organization as well. Notably, to a certain degree, the efforts to make KM successful could affect the component of human capital in the organization (Piri et al., 2013).

Knowledge management of organization affects IC creation, construction and maximization, and IC could be increased using KAP. Furthermore, literature has indicated human capital as the most likely to be impacted by KAP. As such, KAP mediates the accumulation of IC (Azmawani et al., 2013). Meanwhile; acquisition of new knowledge becomes easier with KM. This implies that organizations that successfully apply the process of KM have clear comprehension of what they are lacking (Ramadan et al., 2017). The essential role of the sources of knowledge acquisition in lending support to the efforts of an organization in improving their present organizational knowledge has been recognized. Knowledge acquisition relates to the capacity of the organization in identifying, capturing, and organizing knowledge obtained from outside sources whereby the sought after 
knowledge is of value to the operation of the organization. Knowledge acquisition entails the amassing of fresh knowledge and the updating of already available knowledge (Al-dujaili, 2012), and it highly contributes to the development of HC. As indicated by Dahiyat and Al-Zu'bi (2012), the acquisition of knowledge at the individual level can lead to superior cognitive attitudes, skills, and competences among employees. Hence, the belief is that the important contribution by the $\mathrm{HC}$ of an organization to its economic success, is improved activities of knowledge acquisition that are systematically done, by way of establishing the skills, abilities as well as competencies of the members of the organization. Furthermore, Seleim and Khalil (2011) confirmed that being involved in activities of systematic knowledge acquisition particularly in obtaining externally generated knowledge via knowledge networks formation, assists in establishing exceptional relationships with organization. The obtained knowledge will replace the old knowledge possessed by employees particularly that pertaining to processes or methods processes, and this can greatly affect the organization's improvement of human capital (Hasani and Sheikhesmaeili, 2016).

The current anticipation is that knowledge acquisition will considerably affect the performance of organization. In this regard, Cho and Korte (2014) view knowledge acquisition as comprising the process of obtaining knowledge from both inside or outside of the organizations. When knowledge is aptly acquired, the knowledge that organization possess will increase. This in turn increases the capacity of the organization to make well-timed decisions which are crucial in reaching better performance (Peachey, 2006), external acquisition or learning is necessary for the establishment of wider knowledge base (knowledge exploration) (Sáez et al., 2010). Debatably, external sources of knowledge are crucial in the establishment of an efficacious process of explorative learning. Hence, it is crucial that organizations consistently obtain varied and fresh external knowledge to catalyze future technological and market developments. External knowledge is valuable as it greatly assists in dealing with knowledge obsolescence as well as in exploiting regional and social economies.

The capacity in acquiring new knowledge from an outside source is a form of integrative competency. As mentioned, human capital is consistently seeking knowledge that could resolve their immediate issues and at the same instance, knowledge allows them to make plan for the forthcoming needs and issues. Organizations that fail to acquire new knowledge and learn may fail to survive the dynamics within their industry. These organizations may also fail to forecast the change in customer requirements (Lavie, 2006). By converting knowledge into pertinent organizational knowledge, organizations could improve their expertise and efficiency, and disseminate it where it is required (Pacharapha and Ractham, 2012). A reasonable format is necessary for knowledge storage therefore technologies such as database management and data warehouse are useful as they enable access to people (Pinho, 2013). Meanwhile, documentation assists people in internalizing what they experienced, and therefore, it enriches the tacit knowledge that people possess. In addition, the use of documents or manuals eases the transfer of explicit knowledge to others, and this assists the receiver to indirectly go through the experience (Ha et al., 2015). Documentation of knowledge involves the processes of applying documented knowledge during sessions of brainstorming for solving issues of organization. Furthermore, the documented project success and failures are taken into consideration, and the procedures and handbooks are amended as necessary. Further, the documented knowledge also promotes organizational innovation via the innovative behavior manifested by the employees, whereby information and knowledge are generated and managed (Piri et al., 2013). Documentation of knowledge lends support to human capital because the documented product failures and successes allow employees to learn effectively As a result organizations could discover solutions for problems created by these failures (Piri et al., 2103).

Considering that knowledge documentation improves the skills of problem-solving of employees, and it also adds certain value to the components of human capital of employees (Rohlfer and Zhang, 2016), also, knowledge documentation has considerably allowed knowledge storage, which is usually in the form of organizational memory $(\mathrm{OM})$. In this form, knowledge can be transferred effortlessly aside from becoming accessible and usable as well. OM is identified as an asset that is intangible, and if managed efficiently, it can confer diverse organizational capital (OC) forms. Also, in order that organization's IC can be improved with knowledge creation, the knowledge in question has to be codified, which will allow the documentation, and storage later on. As such, loss of organizational collective knowledge can be prevented (Cardoso et al., 2012). In the context of organizational learning, both documentation and transfer of experience are important. Therefore, tacit and explicit knowledge, and experience possessed by organization members must be available so that these could be extracted. Further, documentation of acquired procedures, techniques and lessons is necessary to enable the transfer of individual and social experiences to others. It also highly contributes to the organization's overall knowledge continuum (Navidi et al., 2017).

Positive and significant impact of KMPs on SC has been reported in the literature. As mentioned, KMP includes 
knowledge acquisition, knowledge application, knowledge creation, knowledge documentation, and knowledge transfer (Sabri and Rayyan, 2014). A new approach has been adopted by innovative organizations. In particular, these organizations adhere to the knowledge retention strategy to benefit all, rather than concentrating on the amassing of personal knowledge. In general, the systematic invaluable knowledge and experiences retention which is accompanied by suitable process of transfer for knowledge and experiences can bring forth considerable economic and industrial benefits. These include time saving, prevention of past mistake repetition, as well as prevention of usage of funds towards hardware and software particularly for the funds intended for acquiring experience (Sohrabi, 2015).

Accordingly, the benefits of documentation system include: the generation of organizational strategy from the sharing of experiences obtained among organization members, creation of a mutual sense and vision, and experience transfer, easier information and experience flow, availability of conducive environment to exchange experiences and ideas by way of learning teams, creation, improvement and the delivery of ideas, knowledge, capacity, and innovation, delivery of organizational development via experience exchange, improved organizational productivity (Sáez et al., 2010). Based on the deliberation above, this study presents the hypotheses as follows:

H1: There is a positive and significant effect of knowledge acquisition on HC.

$\mathrm{H} 2$ : There is a positive and significant effect of knowledge acquisition on knowledge documentation.

H3: There is a positive and significant effect of knowledge documentation on HC.

H4: There is a positive and significant mediating effect of knowledge documentation on the relationship between knowledge acquisition and $\mathrm{HC}$.

\subsection{Organizational Culture - KDP Relationship}

Organizational culture comprises the norm which provides guidance to people's attitude as well as behavior in an organization. Organizational culture is thus highly significant as it greatly affect the success requirements. These requirements include: customer service, efficiency, innovation, product reliability, and quality. Hence it is necessary to have the knowledge on how organizational culture facilitates the processes of knowledge (Sun, 2010). In the context of KM, organizational culture is a critical success factor), and the most crucial conditions for successful KM project (Tong and Mitra, 2009; Seleim and Khalil, 2011). The success of KM initiatives requires a culture that values idea sharing (Tseng, 2016). As emphasized by Peachey (2006), even the best initiatives of KM cannot succeed without the presence of culture that willingly accepts change. KM initiatives adoption is in fact impacted by organizational culture, considering that organizational culture affects employee behavior. Organizational culture is also highly crucial in the facilitation of knowledge creation, transfer, application and documentation (Sabri and Rayyan, 2014; Sangari et al., 2015). Organization with a tightly controlled culture can document knowledge easier, and therefore, in this culture, it appears easier to embed the past knowledge into the process of the organization, resulted in forming stable knowledge base and knowledge memory. On the other hand, organizations that embrace a loosely controlled culture uphold the notions of freedom and flexibility. Such culture appears to be unfit for documentation and knowledge memory (Sun, 2010). As such, the following hypothesis is presented:

H5: There is a positive and significant effect of organizational culture on knowledge documentation.

\section{Methodology}

\subsection{Sample and Data Collection}

The data used in this study came from self-report questionnaire distributed randomly to selected individuals working for national agriculture research center (NARC) in Jordan. The NARC contains a large number of staff at various administrative levels. It has more than 980 employees, some of which are administrative staff who work in daily routines, such as secretaries, human resources, and accountants while others are classified by the center as "agricultural researchers" who represent the study sample, estimated 340 researchers (ncare.gov.jo). The selection of sample study was due to several factors, have strong external knowledge acquisition practices. Accordingly, all researchers attended training courses, workshops in addition to attending science related conferences in internationally reputable scientific centers. Sample of the study contains all agricultural researchers "340 researchers" from different ranks to complete the questionnaire. The respondents were all assured of confidentiality with respect to procedures and collected data. A total of 324 usable responses were obtained.

Demographic data provides the main attributes of the participating respondents which is included in the 
questionnaire instrument. These attributes include basic information about the respondents education, gender, position, years of experience. Table 1 shows these attributes.

Table 1. Demographic data for respondents

\begin{tabular}{lll}
\hline Category & Frequency & Percentage \% \\
\hline Gender & & \\
Male & 191 & 59 \\
Female & 133 & 41 \\
Education & & \\
Bachelor's Degree & 198 & 61.1 \\
Masters Degree & 102 & 31.5 \\
PhD Degree & 24 & 7.4 \\
Experience & & \\
Less than 5 years & 123 & 38 \\
5 - Less than 10 years & 147 & 45.4 \\
10 - Less than 15 years & 39 & 12 \\
15 years and above & 15 & 4.6 \\
Position & & \\
Lower management & 186 & 57.4 \\
Middle management & 103 & 31.8 \\
Top management & 35 & 10.8 \\
\hline
\end{tabular}

\subsection{Operational Measures}

Following the review made on the related previous work, theoretical framework and the key constructs of this study were determined. Then, the key constructs (KAP, KDP, HC, and OC) were provided with their own operational definition, and as their measurement, several items were constructed. In this study, a questionnaire was determined as the primary data gathering instrument, and it was constructed based on the administrative literature that is associated with the context of this study. The five-point Likert scale was provided to allow the respondents to denote their degree of agreement on each item. Specifically, the scale of "1" denotes "strongly disagree" while the scale of " 5 " denotes "strongly agree".

This study attempts to demonstrate the direct impact imparted by the independent variables on the dependent variable, and the indirect impact imparted by the independent variables on the dependent variable when mediator variable is present. The questionnaire is made up of four parts. The first one comprises items on the demographic information of the respondents such as gender, level of education, position, and years of experience. As for the second part, it comprises the paragraphs measuring the independent variables' dimensions.

For the construct of Knowledge acquisition (KAP), it entails a process of gathering information from diverse external sources and having the information embedded into the already available knowledge of individual. A total of 8 items (KAP1-KAP8) are used to measure KA, in accordance to previous works (i.e., Ramadan et al., 2017; Sáez et al., 2010; Azmawani et al., 2013). Meanwhile, the construct of knowledge documentation (KDP) denotes the processes through which knowledge is maintained and organized research is facilitated, accessible and to get it. KDP is measured using 7 items (KDP1-KDP7) adopted from past researches (i.e., Ortiz et al., 2017; Ramadan et al., 2017; Kianto et al., 2016; Tseng, 2010). Further, the construct of human capital (HC) comprises the accumulation of staff knowledge, experience, competence, attitude, experiments, commitment, and wisdom, representing the knowledge base of the members of the organization in achieving certain goals. HC is measured by 7 items (HC1-HC7) grounded on the previous literature (i.e., Bontis, 1998; Hsu and Sabherwal, 2011). Meanwhile, the construct of organization Culture (OC) relates to the rules and behavior which function as guidance to employee's behavior. This construct is measured using 7 items (OC1-OC7) based on the works of (Theriou et al., 2011; Birasnav and Rangnekar, 2010).

\section{Results}

Table 2 shows the Mean, Standard Deviation (SD), standardized factor loadings of and average variance extracted (AVE), Cronbach's alpha values and composite reliability of the order constructs. 
Table 2. Descriptive and reliability statistics

\begin{tabular}{|c|c|c|c|c|c|c|}
\hline Construct & Item & Loadings & Mean & SD & $\alpha$ & AVE \\
\hline \multirow{8}{*}{ Acquisition Knowledge } & KAP1 & 0.6541 & 3.99 & 0.66 & \multirow[t]{8}{*}{0.91} & \multirow[t]{8}{*}{0.652} \\
\hline & KAP2 & 0.8237 & 4.01 & 0.61 & & \\
\hline & KAP3 & 0.8646 & 3.98 & 1.00 & & \\
\hline & KAP4 & 0.8702 & 4.12 & 0.65 & & \\
\hline & KAP5 & 0.6341 & 4.34 & 0.65 & & \\
\hline & KAP6 & 0.7347 & 3.98 & 0.66 & & \\
\hline & KAP7 & 0.6655 & 4.14 & 1.00 & & \\
\hline & KAP8 & 0.8643 & 4.22 & 0.61 & & \\
\hline \multirow{7}{*}{ Documentation Knowledge } & KPD1 & 0.7401 & 3.03 & 1.01 & \multirow[t]{7}{*}{0.84} & \multirow[t]{7}{*}{0.542} \\
\hline & KPD2 & 0.6731 & 3.05 & 1.04 & & \\
\hline & KPD3 & 0.6945 & 3.02 & 1.01 & & \\
\hline & KPD4 & 0.7550 & 3.23 & 1.21 & & \\
\hline & KPD1 & 0.6231 & 3.33 & 1.24 & & \\
\hline & KPD2 & 0.6215 & 3.43 & 1.01 & & \\
\hline & KPD3 & 0.5430 & 3.12 & 1.02 & & \\
\hline \multirow{7}{*}{ Human Capital } & $\mathrm{HC} 1$ & 0.6870 & 3.89 & 0.94 & \multirow[t]{7}{*}{0.82} & \multirow[t]{7}{*}{0.761} \\
\hline & $\mathrm{HC} 2$ & 0.6563 & 4.11 & 0.71 & & \\
\hline & $\mathrm{HC} 3$ & 0.7482 & 3.98 & 065 & & \\
\hline & $\mathrm{HC} 4$ & 0.8132 & 4.04 & 0.87 & & \\
\hline & $\mathrm{HC} 5$ & 0.7616 & 4.02 & 0.94 & & \\
\hline & HC6 & 0.7541 & 3.92 & 0.97 & & \\
\hline & $\mathrm{HC} 7$ & 0.6438 & 4.00 & 0.88 & & \\
\hline \multirow{7}{*}{ Organization Culture } & $\mathrm{OC} 1$ & 0.7579 & 3.69 & 0.66 & \multirow[t]{7}{*}{0.86} & \multirow[t]{7}{*}{0.674} \\
\hline & $\mathrm{OC} 2$ & 0.8334 & 3.68 & 0.68 & & \\
\hline & OC3 & 0.8287 & 3.44 & 0.69 & & \\
\hline & OC4 & 0.7938 & 3.21 & 0.78 & & \\
\hline & OC5 & 0.7567 & 3.02 & 0.62 & & \\
\hline & OC6 & 0.7343 & 3.11 & 0.67 & & \\
\hline & OC7 & 0.7532 & 3.12 & 0.67 & & \\
\hline
\end{tabular}

Table 1 shows that all the factor loadings were higher than 0.50 . Also, average variance extracted (AVE) values for all the constructs exceeded 0.50 supporting the convergent validity. The composite reliability of the order constructs exceeded 0.70 indicating sufficient levels of reliability 0.80 ; the Cronbach's coefficients for the resulting variable between 0.82 and 0.91 . Table 3 shows the correlation coefficient of the variables used in this paper. The coefficients of correlations confirmed, significant among independent, mediator, and dependent variables. The results shown in Table 2 confirmed the relationship between KAP (0.53), KDP (0.32), and HC. OC is also correlated with KDP (0.345). Also confirmed the positive relationships between KAP and KDP (0.304). In support of these relationships, the mediating effect of KDP in the association between knowledge Acquisitions Process (KAP) and $\mathrm{HC}$ can be analyzed.

Table 3. Correlations coefficient means, standard deviations, correlations coefficient of order constructs

\begin{tabular}{llllll}
\hline Constructs & Mean & SD & KAP & KAD & OC \\
KAP & 3.67 & 0.760 & 1 & & \\
KDP & 3.41 & 0.714 & $0.304 *$ & 1 & \\
OC & 3.48 & 0.865 & ------- & $0.3453^{*}$ & 1 \\
HC & 3.63 & 0.746 & $0.539 *$ & $0.534^{*}$ & ------- \\
\hline
\end{tabular}

Notes:(1) Knowledge Acquisition Process KAP, Knowledge Documentation Process KDP, Organization Culture OC, Human Capital HC; (2)..... is the relationship between the variables are not analyses.

The causal steps approach known as the Baron and Kenny's (1986) method was used to examine the paper hypotheses and confirm the mediation effect of knowledge documentation between knowledge acquisition and human capital. As well as the Organization's culture as a decisive and encouraging factor for the documentation 
of knowledge, Figure 2 demonstrates the results of the causal steps approach. In the first regression model, the knowledge acquisition (independent variable) should predict the Human Capital (dependent variable), knowledge acquisition was significantly related to Human Capital, $(\beta=0.454, p<0.001)$. Therefore hypothesis H1 was accepted.

In the second regression model, knowledge acquisition (the independent variable) was significantly related to knowledge documentation (the mediator) providing support for hypothesis $\mathrm{H} 2(\beta=0.346, \mathrm{p}<0.001)$. In the third regression model, knowledge documentation (the mediator) was significantly related to human capital (the dependent variable) providing support for hypothesis $\mathrm{H} 3(\beta=0.424, \mathrm{p}<0.001)$.

Table 4. Regression analysis for mediation of the effect of knowledge acquisition on human capital through knowledge documentation

\begin{tabular}{|c|c|c|c|c|}
\hline Variables & $\begin{array}{l}\text { Step 1 } \\
\text { Human Capital }\end{array}$ & $\begin{array}{l}\text { Step } 2 \\
\text { Knowledge Documentation }\end{array}$ & $\begin{array}{l}\text { Step } 3 \\
\text { Human Capital }\end{array}$ & $\begin{array}{l}\text { Step } 4 \\
\text { Human Capital }\end{array}$ \\
\hline (Constant) & 2.561 & 2.410 & 2.750 & 2.243 \\
\hline Knowledge Acquisition & 0.454 & 0.346 & & 0.354 \\
\hline Knowledge Documentation & & & 0.424 & 0.264 \\
\hline $\mathrm{R}$ & 0.462 & 0.431 & 0.324 & 0.542 \\
\hline $\mathrm{R}^{2}$ & 0.353 & 0.234 & 0.247 & 0.309 \\
\hline F-Value & $40.634 *$ & 44.421 & 43.421 & 46.187 \\
\hline
\end{tabular}

Note. $\mathrm{p} \leq 0.01$.

In the fourth regression model, both knowledge acquisition and knowledge documentation (the independent variable and the mediator) were regressed together to predict human capital (the dependent variable). As shown in Table 4, the direct effect of knowledge acquisition on human capital in the first regression model $(\beta=0.454$, $p$ $<0.001)$ was reduced in the fourth regression model, but still significant $(\beta=0.354, \mathrm{p}<0.001)$ implying that only partial mediation effect may exist. To calculate the indirect effect according to Baron and Kenny's (1986), the regression coefficient obtained from regressing the mediator to predict the human capital (dependent variable) ( $\beta=0.424$ ) should be multiplied by the regression coefficient obtained from regressing the knowledge acquisition independent variable to knowledge documentation predict the mediator $(\beta=0.346)$. Thus, the indirect effect of knowledge acquisition on knowledge documentation through knowledge documentation $=$ $0.424 *=0.346=0.145$. Figure 2 and Figure 3 demonstrate direct and indirect effects.

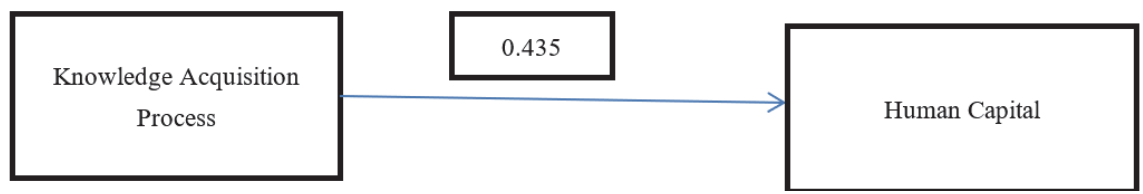

Figure 2. Knowledge acquisition-human capital model. Note: $\mathrm{p}<0.001$.

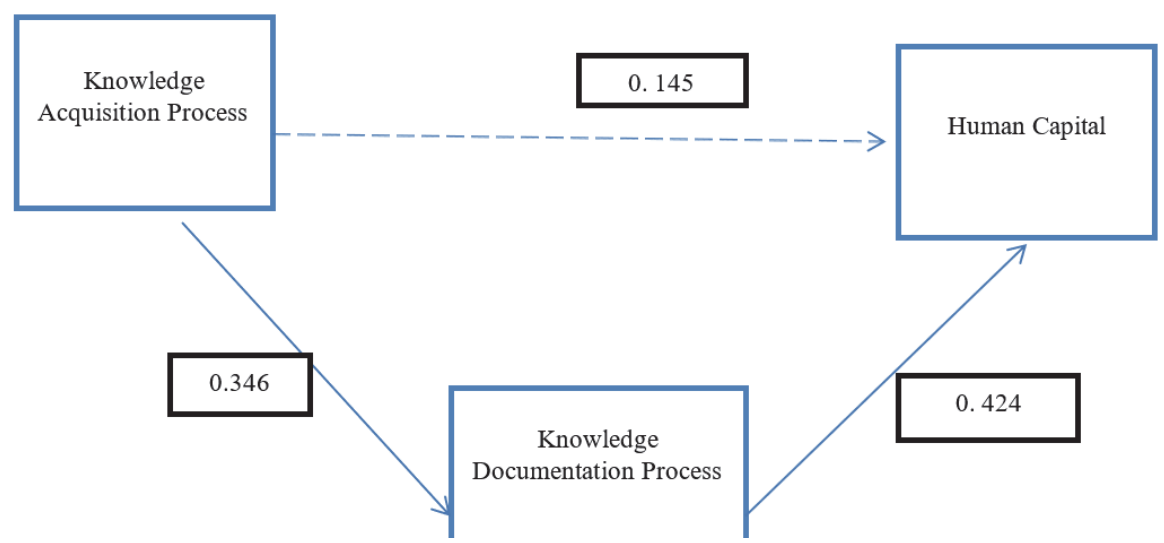

Figure 3. Knowledge acquisition - knowledge documentation-human capital model. Note: $\mathrm{p}<0.001$; a: indirect effect 


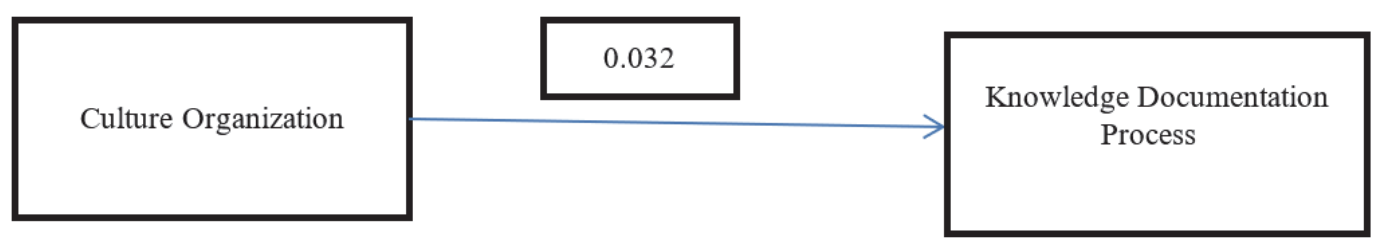

Figure 4. Organization's culture-Knowledge documentation process model. Note: $\mathrm{p}<0.001$.

Table 5. The results of single regression analysis indicate that the organization's culture affects the knowledge documentation

\begin{tabular}{lllllll}
\hline & $\mathrm{R}$ & $\mathrm{R}^{2}$ & $\mathrm{~F}$ & $\mathrm{~B}$ & $\mathrm{t}$-value & $\mathrm{Sig}$ \\
\hline Organization's Culture & 0.19 & 0.0361 & 17.67 & 0.8 & 0.032 & 0.431 \\
\hline
\end{tabular}

Note. $\mathrm{p}<0.001$

Table 5 shows that organization's culture however, was found to have an insignificant and weak effect on knowledge documentation. The value of $\beta$ is 0.032 , which a small value and not significant at $(\mathrm{p} \leq 0.05)$, sig 0.431 .

\section{Discussion and Conclusion}

This study presents an empirically tested comprehensive model in order to examine HC from a "knowledge process"-based perspective. This study hypothesized and investigated the effect of two KMP, namely knowledge acquisition and knowledge documentation, on HC. Additionally, this study attempted to ascertain the important mediating role of knowledge documentation in leveraging the effect of knowledge acquisition on HC development. The crucial role played by organizational culture in leveraging the effect of knowledge documentation on $\mathrm{HC}$ development was examined as well.

The obtained findings empirically support the conjecture that HC development is positively impacted by KMPs, particularly with respect to the process of knowledge acquisition. These findings are significant from both theoretical and empirical aspects in addition to those works on the interconnections between some knowledge processes and dimensions of IC (Piri et al., 2013; Wiig, 1997; Seleim and Khalil, 2011). Relevantly, Boateng et al. (2014) emphasized the importance of knowledge acquisition by stating that employees seek for knowledge that could resolve their immediate problems and enable them to make plan to cater to forthcoming needs and problems. Inability in acquiring new knowledge as well as in learning can lead to failure to organization in keeping up with the dynamics within its industry. This organization may also be unable to predict changes in the needs of its customer (Obeidat et al., 2017). Knowledge acquisition is regarded as an essential KM process because it enables organizations to improve their performance and effectiveness through the improvement of the breadth and depth of the accessible knowledge. In addition, organizations with successful knowledge acquisition appear to possess knowledge base that is richer and more diverse, aside from appearing more innovative. For any organization, knowledge acquisition is an essential process because learning from external sources will expand the organization's knowledge bases and resulted in having better ability in recognizing opportunities and threats, and have more access to new competences.

These findings contradict Ramadan et al (2017) who asserted that knowledge documentation is the most vital process with respect to its impact on HC development. They confirmed that for HC to develop and accumulate within an organization, the created knowledge within organization has to be stored and documented. Documentation of knowledge combined with transfer is crucial in the facilitation of human-embodied knowledge sharing via the transformation of embodied knowledge into non-embodied one (i.e. OC and OM). The finding of this study further denotes the emphasis that is rested on the creation of knowledge. According to Kianto et al. (2016) knowledge documenting and storing tasks practiced in an organization, sharing of knowledge through interactions within organization, and the presence of external knowledge acquisition will lead to access to material for the process of knowledge creation. Consequently, the level of intellectual assets owned by the organization, accumulation of $\mathrm{HC}$, will be improved.

As shown in the results, a strong relationship appears to be present between knowledge acquisition and its effect on human capital. Interestingly, KDP does not appear to adequately impact HC, because organization culture does not appear to be encouraging knowledge documentation. Conversely, Allameh et al. (2011) pointed that 
culture impacts behavior which has linkage to knowledge, people, groups, organizational divisions, and the organization in its entirety. Organizational culture also critically impacts the decision pertaining to when, where and with whom a given knowledge should be exchanged. Furthermore, within the domain of knowledge management and organizational learning, organizational culture has been deemed to be the most powerful factor. The organizational culture that is conducive to the fostering of KM activities should be created. The behavior of employees pertaining to knowledge acquisition and documentation is a clear demonstration of organizational culture (Akhavan et al., 2014b). Furthermore, Mian et al. (2009) emphasized the importance of having the understanding that in organizations, knowledge documentation and learning is highly influenced by the cultural values embraced by the organization and its members.

The aim of this paper is to investigate the impact knowledge acquisition process, knowledge documentation process, on human capital, and impact organizational culture on documentation process the disposition of the mediating role of knowledge documentation in the context of KAP and $\mathrm{HC}$, the invaluable role played by organizational culture in leveraging the effect of knowledge documentation were also investigated. This study also highlighted the role of culture embraced by organization in encouraging human capital to document its acquired knowledge. As shown by the findings, KAP appears to have the strongest impacts on HC. Meanwhile, the impact of knowledge acquisition appears to be insignificant on documentation, whereas, KDP was found to be a strong mediator of the effects of knowledge acquisition on HC.

This study followed a different approach in looking at the links between KM processes and HC. A suggested model was presented and it includes the past outcomes on the impact of each knowledge management process on human capital. Knowledge documentation has been investigated as a mediating variable in affecting the development of HC. Furthermore, the role of culture that organization embraces was this study's independent variable impacting documentation of knowledge. The examined literature examined the effect of the processes of knowledge management on intellectual capital, and the direct relations of these processes on human capital. However, they did not examine neither the mediator's role on knowledge documentation.nor considering the effect of the variables of infrastructure of knowledge management on the processes of knowledge management as the culture practiced by the organization (Kushwaha and Rao, 2015; Mehralian et al., 2014; Piri et al., 2013; Sohrabi, 2015).

A number of recommendations are presented in this study as an attempt to promote human capital development, with the focus on the managers in the knowledge documentation domain, individuals who manage knowledge especially those in NCRA should pay attention to knowledge documentation seeing that documentation is invaluable in knowledge preservation. Preservation of knowledge will prevent duplication and mistakes repetition. In other words, in the context of employees of organization, the new employees will learn what was acquired by their predecessors through knowledge preservation. The culture embraced by the organization should promote values that encourage employees to document knowledge. Also, tools and means for knowledge documentation should be made available, as it will strengthen and consolidate knowledge within the organization while also improving knowledge retrieval process particularly in terms of capability and effectiveness. The organization should also make available the human resources that specialize in the documentation of knowledge obtained from external sources. Eventually members of organization can consult these human resources. Documentation of knowledge prevents loss of knowledge when members of organization leave for any reason. Furthermore, as knowledge obtained from external sources could expand the knowledge bases of organization while also improving the organization's recognition of opportunities and threats, and access to new abilities, knowledge documentation remains an invaluable practice in any organization.

Taking into account the disposition of knowledge and intellectual capital of the members of organization, loss of tacit knowledge is highly occur when these members leave the organization which could happen due to a number of reasons including retirement, transfer to other branches, and structural modifications made to the organization. Documentation as well as experience transfer is important to organizational learning. Accordingly, appropriate exploitation of the experience, in addition to the explicit and tacit knowledge possessed by the members of organization members is necessary.

\section{References}

Abualoush, S. H., Obeidat, A. M., Tarhini, A., Masa'deh, R., \& Al-Badi, A. (2018). The role of employees' empowerment as an intermediary variable between knowledge management and information systems on employees' performance. VINE Journal of Information and Knowledge Management Systems, 48(2), 217-237.

Abualoush, S., Bataineh, K., \& Alrowwad, A. (2018). The role of knowledge management process and 
intellectual capital as intermediary variables between knowledge management infrastructure and organization performance. Interdisciplinary Journal of Information, Knowledge, and Management, 13, 279-309.

Adewale, O. O., \& Anthonia, A. A. (2013). Impact of organizational culture on human resource practices: A study of selected Nigerian private universities. Journal of Competitiveness, 5(4), 115-133.

Akbari, N., \& Ghaffari, A. (2017). Verifying relationship of knowledge management initiatives and the empowerment of human resources. Journal of Knowledge Management, 21(5), 1120-1141.

Akhavan, P., Ramezan, M., Moghaddam, J. Y., \& Mehralian, G. (2014a). Exploring the relationship between ethics, knowledge creation and organizational performance: Case study of a knowledge-based organization. VINE: The Journal of Information and Knowledge Management Systems, 44(1), 42-58.

Akhavan, P., Sanjaghi, M. E., Rezaeenour, J., \& Ojaghi, H. (2014b). Examining the relationships between organizational culture, knowledge management and environmental responsiveness capability. VINE: The Journal of Information and Knowledge Management Systems, 44(2), 228-248.

Al Saifi, S. A. (2015). Positioning organisational culture in knowledge management research. Journal of Knowledge Management, 19(2), 164-189.

Alavi, M., \& Leidner, D. (2001). Review: knowledge management and knowledge management systems: Conceptual foundations and research issues. MIS Quarterly, 25(1), 107-36.

Al-dujaili, M. A. (2012). Influence of intellectual capital in the organizational innovation. International Journal of Innovation, Management and Technology, 3(2), 128-135.

Alkandari, A., Masa'deh, R., \& Al-Lozi, M. (2017). Knowledge management and its role on organizational crisis management: A literature review. Journal of Social Sciences (COES\&RJ-JSS), 6(4), 833-850.

Allameh, S. M., Zare, S. M., \& Davoodi, S. M. R. (2011). Examining the impact of KM enablers on knowledge management processes. Procedia-Computer Science, 3, 1211-1223.

Analoui, B. D., Doloriert, C. H., \& Sambrook, S. (2012). Leadership and knowledge management in UK ICT organizations. Journal of Management Development, 32(1), 4-17.

Azmawani, A. R., Siew, I. N., Murali, S., \& Florence, W. (2013). Training and organizational effectiveness: Moderating role of knowledge management process. European Journal of Training and Development, 37(5), $472-488$.

Baron, R. M., \& Kenny, D. A. (1986). The moderator-mediator variable distinction in social psychological research: conceptual, strategic, and statistical considerations. Journal of Personality and Social Psychology, 51(6), 1173-1182.

Bastos, R. (2017). A human capital measurement scale. Journal of Intellectual Capital, 18(2), 316-329.

Bavik, A. (2016). Identification of organizational culture in the hospitality industry. In Metin Kozak \& Nazmi Kozak (Eds.), Tourism and Hospitality Management (Advances in Culture). Tourism and Hospitality Research, 12, 197-210.

Birasnav M., \& Rangnekar, S. (2010). Knowledge management structure and human capital development in Indian manufacturing industries. Business Process Management Journal, 16(1), 57-75.

Birasnav, M., Rangnekar, S., \& Dalpati, A. (2011). Transformational leadership and human capital benefits: The role of knowledge management. Leadership \& Organization Development Journal, 32(2), 106-126.

Boateng, H., Dzandu, M., \& Tang, Y. (2014). An investigation into knowledge acquisition idiosyncrasies in Ghanaian universities. VINE: The Journal of Information and Knowledge Management Systems, 44(4), 579-591.

Bontis, N. (1998). Intellectual capital: An exploratory study that develops measures and models. Management Decision, 36(2), 63-76.

Bose, R. (2004). Knowledge management metrics. Industrial Management \& Data Systems, 104(6), 457-468.

Cardoso, L., Meireles, A., \& Peralta, C. (2012). Knowledge management and its critical factors in social economy organizations. Journal of Knowledge Management, 16(2), 267-284.

Chang, C. L. H., \& Lin, T. C. (2015). The role of organizational culture in the knowledge management process. Journal of Knowledge Management, 19(3), 433-455. 
Cho, T., \& Korte, R. (2014). Managing knowledge performance: Testing the components of a knowledge management system on organizational performance. Asia Pacific Education Review, 15(2), 313-327.

Claver-Cortés, E., Zaragoza-Sáez, P. C., Molina-Manchón, H., \& Úbeda-García, M. (2015). Intellectual capital in family firms: Human capital identification and measurement. Journal of Intellectual Capital, 16(1), 199-223.

Dahiyat, S. E., \& Al-Zu'bi, Z. M. F. (2012). The role of knowledge acquisition in facilitating customer involvement in product development: Examining the mediation effect of absorptive capacity. International Journal of Learning and Change, 6(4), 171-206.

Dehghani, M., \& Akhavan, P. (2017). An experimental investigation of knowledge acquisition techniques. Journal of Management Development, 36(4), 493-514.

Durst, S., \& Edvardsson, I. R. (2012). Knowledge management in SMEs: A literature review. Journal of Knowledge Management, 16(6), 879-903.

Edvardsson, I. R. (2006). Knowledge management and SMEs: The case of Icelandic firms. Knowledge Management Research \& Practice, 4(4), 275-282.

Edvardsson, I. R. (2008). HRM and knowledge management. Employee Relations, 30(5), 553-561.

Felício, A., Couto, E., \& Caiado, J. (2014). Human capital, social capital and organizational performance. Management Decision, 52(2), 350-364.

Filius, R., de Jong, J. A., \& Roelofs, E. C. (2000). Knowledge management in the HRD office: A comparison of three cases. Journal of Workplace Learning, 12(7), 286-295.

Gamerschlag, R. (2013). Value relevance of human capital information. Journal of Intellectual Capital, 14(2), 325-345.

Gold, A. H., Malhotra, A., \& Segars, A. H. (2001). Knowledge management: An organizational capabilities perspective. Journal of Management Information Systems, 18(1), 185-214.

Ha, S. T., Lo, M. C., \& Wang, Y. C. (2015). Relationship between knowledge management and organizational performance: A test on SMEs in Malaysia. Procedia-Social and Behavioral Sciences, 224, 184-189.

Hasani, K., \& Sheikhesmaeili, S. (2016). Knowledge management and employee empowerment: A study of higher education institutions. Kybernetes, 45(2), 337-355.

Ho, C. F., Hsieh, P. H., \& Hung, W. H. (2014). Enablers and processes for effective knowledge management. Industrial Management \& Data Systems, 114(5), 734-754.

Honarpour, A., Jusoh, A., \& MdNor, K. (2012). Knowledge management, total quality management and innovation: A new look. Journal of Technology Management \& Innovation, 7(3), 22-31.

Hsieh, C. T., Yang, H., \& Lin, B. (2002). Roles of knowledge management in online procurement systems. Industrial Management \& Data Systems, 102(7), 365-370.

Hsu, I. C., \& Sabherwal, R. (2011). From intellectual capital to firm performance: The mediating role of knowledge management capabilities. IEEE Transactions on Engineering Management, 58(4), 626-642.

Huang, Y., \& Wu, Y. J. (2010). Intellectual capital and knowledge productivity: The Taiwan biotech industry. Management Decision, 48(4), 580-599.

Kamaruzzaman, S. N., Zawawi, E. M., Shafie, M. O., \& Mohd Noor, S. N. (2016). Assessing the readiness of facilities management organizations in implementing knowledge management systems. Journal of Facilities Management, 14(1), 69-83.

Kateb, M., Swies, R., Obeidat, B., \& Maqableh, M. (2015). An investigation on the critical factors of information system implementation in Jordanian information technology companies. European Journal of Business and Management, 7(36), 11-28.

Khan, I. U., Usoro, A., \& Majewski, G. (2012). An organizational culture model for comparative studies and assessment of IT projects. International Journal of Human Capital and Information Technology Professionals, 3(2), 63-83.

Kianto, A., Vanhala, M., \& Heilmann, P. (2016). The impact of knowledge management on job satisfaction. Journal of Knowledge Management, 20(4), 621-636.

King, W. R. (2009). Knowledge management and organizational learning. Annals of Information Systems, 4, 
Springer Science Business Media, LLC.

Kushwaha, P., \& Rao, M. K. (2015). Integrative role of KM infrastructure and KM strategy to enhance individual competence: Conceptualizing knowledge process enablement. VINE: The Journal of Information and Knowledge Management Systems, 45(3), 376-396.

Lavie, D. (2006). The competitive advantage of interconnected firms: An extension of the resource-based view. Academy of Management Review, 31(3), 643-647.

Liao, S. H, Wu, C. C., Hu, D. C., \& Tsuei, G. A. (2009). Knowledge acquisition, absorptive capacity, and innovation capability: An empirical study of Taiwan's knowledge-intensive industries. International Journal of Mechanical and Industrial Engineering, 3(5), 338-345.

Lin, H. (2014). A multi-stage analysis of antecedents and consequences of knowledge management evolution. Journal of Knowledge Management, 18(1), 52-74.

Marr, B., Schiuma, G., \& Neely, A. (2004). Intellectual capital: Defining key performance indicators for organizational knowledge assets. Business Process Management Journal, 10(5), 551-569.

Masa'deh, R. (2016). The role of knowledge management infrastructure in enhancing job satisfaction at Aqaba five star hotels in Jordan. Communications and Network, 8(4), 219-240.

Masa'deh, R., Hunaiti, Z., \& Bani Yaseen, A. (2008). An integrative model linking IT-business strategic alignment and firm performance: The mediating role of pursuing innovation and knowledge management strategies. Communications of the International Business Information Management Association (IBIMA) Journal, 180-187.

Masa'deh, R., Shannak, R., Maqableh, M., \& Tarhini, A. (2017). The impact of knowledge management on job performance in higher education: The case of the University of Jordan. Journal of Enterprise Information Management, 30(2), 244-262.

McCann, J. E., \& Buckner, M. (2004). Strategically integrating knowledge management initiatives. Journal of Knowledge Management, 8(1), 47-63.

Mehralian, G., Nazari, J. A., Akhavan, P., \& Rasekh, H. R. (2014). Exploring the relationship between the knowledge creation process and intellectual capital in the pharmaceutical industry. The Learning Organization, 21(4), 258-273.

Meng, F., Wang, X., Chen, H., Zhang, J., Yang, W., Wang, J., \& Zheng, Q. (2016). The influence of organizational culture on talent management: A case study of a real estate company. Journal of Chinese Human Resource Management, 7(2), 129-146.

Mian M., Kekäle, A. T., \& Takala, J. (2009). Cultural impacts on knowledge management and learning in project-based firms. VINE: The Journal of Information and Knowledge Management Systems, 39(4), 339-352.

Mikkawi, B., \& Al-Lozi, M. (2017). The impact of knowledge management infrastructure on academic staff effectiveness: An empirical study at The University of Jordan. Jordan Journal of Business Administration, 13(1), 95-127.

National Agricultural Research Center (NARC). (2018). Retrieved from http://www.ncare.gov.jo

Navidi, F., Hassanzadeh, M., \& Shojai, A. Z. (2017). Organizational knowledge documentation in project-based institutes: A case study at the satellite research institute. The Electronic Library, 35(5), 994-1012.

Nonaka, I., \& Takeuchi, H. (1995). The knowledge creating company: how Japanese companies create the dynamics of innovation. Oxford University Press, New York, NY.

Obeidat, B., Tarhini, A., Masa'deh, R., \& Aqqad, N. (2017). The impact of intellectual capital on innovation via the mediating role of knowledge management: A structural equation modelling approach. International Journal of Knowledge Management Studies, 8(4), 273-298.

Ortiz, B., Donate, M. J., \& Guadamillas, F. (2017). Relationships between structural social capital, knowledge identification capability and external knowledge acquisition. European Journal of Management and Business Economics, 26(1), 48-66.

Pacharapha, T., \& Ractham, V. (2012). Knowledge acquisition: The roles of perceived value of knowledge content and source. Journal of Knowledge Management, 16(5), 724-739.

Peachey, T. A. (2006). An examination of the effects of cultural, climatic, structural, and technological factors on 
knowledge management effectiveness. Unpublished doctoral dissertation, Auburn University, Auburn, AL.

Petruzzelli, A., Albino, V., \& Carbonara, N. (2009). External knowledge sources and proximity. Journal of Knowledge Management, 13(5), 301-318.

Pinho, J. (2013). The role of relational social capital in examining exporter-intermediary relationships. European Business Review, 25(6), 553-570.

Piri, M., Jasemi, M., \& Abdi, M. (2013). Intellectual capital and knowledge management in the Iranian space industries. VINE: The Journal of Information and Knowledge Management Systems, 43(3), 341-356.

Ramadan, B. M., Dahiyat, S. E., Bontis, N., \& Al-dalahmeh, M. A. (2017). Intellectual capital, knowledge management and social capital within the ICT sector in Jordan. Journal of Intellectual Capital, 18(2), 437-462.

Ranjbarfard, M., Aghdasi, M., López-Sáez, P., \& López, J. E. N. (2014). The barriers of knowledge generation, storage, distribution and application that impede learning in gas and petroleum companies. Journal of Knowledge Management, 18(3), 494-522.

Rohlfer, S., \& Zhang, Y. (2016). Culture studies in international business: Paradigmatic shifts. European Business Review, 28(1), 39-62.

Rowley, J. (2004). Partnering paradigms? Knowledge management and relationship marketing. Industrial Management \& Data Systems, 104(2), 149-157.

Sabri, H. A., \& Rayyan, M. (2014). Managing human capital in Arab countries: The leadership and cultural challenges. International Journal of Economics, Commerce and Management, 2(12), 1-9.

Sáez, P. L., López, J. E., de Castro, G., \& González, J. C. (2010). External knowledge acquisition processes in knowledge intensive clusters. Journal of Knowledge Management, 14(5), 690-707.

Sangari, M. S., Reza Hosnavi, R., \& Zahedi, M. R. (2015). The impact of knowledge management processes on supply chain performance: an empirical study. The International Journal of Logistics Management, 26(3), 603-626.

Seleim, A. A. S., \& Khalil, O. E. M. (2011). Understanding the knowledge management- intellectual capital relationship: A two way analysis. Journal of Intellectual Capital, 12(4), 586-614.

Shannak, R., \& Obeidat, B. (2012). Culture and the implementation process of strategic decisions in Jordan. Journal of Management Research, 4(4), 257-281.

Sohrabi, A. (2015). The role of knowledge management practices in developing human capital. International Journal of Economics, Commerce and Management, 3(5), 573-589.

Subramaniam, M., \& Youndt, M. A. (2005). The influence of intellectual capital on the types of innovative capabilities. Academy of Management Journal, 48(3), 450-463.

Sun, P. (2010). Five critical knowledge management organizational themes. Journal of Knowledge Management, 14(4), 507-523.

Tarhini, A., Mgbemena, C., \& Trab, M. S. A. (2015). User adoption of online banking in Nigeria: A qualitative study. Journal of Internet Banking and Commerce, 20(3), 1-8.

Theriou, N., Maditinos, D., \& Theriou, G. (2011). Knowledge management enabler factors and firm performance: An empirical research of the Greek medium and large firms. European Research Studies Journal, 2, 97-134.

Tong, J., \& Mitra, A. (2009). Chinese cultural influences on knowledge management practice. Journal of Knowledge Management, 13(2), 49-62.

Tseng, S. M. (2010). The effects of hierarchical culture on knowledge management processes. Management Research Review, 33(8), 827-839.

Tseng, S. M. (2016). Knowledge management capability, customer relationship management, and service quality. Journal of Enterprise Information Management, $29(2), 202-221$.

Wiig, K. M (1997). Integrating intellectual capital and knowledge management. Long Range Planning, 30(3), $399-405$.

Yusoff, W. F., Jantan, M., \& Ibrahim, D. N. (2004). The interactive effects of human capital, structural capital and social capital on firm performance. Asian Academy of Management Journal, 9(2), 1-18. 


\section{Copyrights}

Copyright for this article is retained by the author(s), with first publication rights granted to the journal.

This is an open-access article distributed under the terms and conditions of the Creative Commons Attribution license (http://creativecommons.org/licenses/by/4.0/). 